\title{
EFFECT OF NURSING CARE PROTOCOL ON DEEP VEIN THROMBOSIS OCCURRENCE AMONG CRITICALLY NEUROLOGICAL PATIENTS
}

\author{
Asmaa Ibrahem Abo Seada ${ }^{1}$, Aml Eid Abdelmoniem Shaaban ${ }^{2}$, Marwa Fathallah Mostafa ${ }^{3}$ \\ Assistant professor of Critical Care and Emergency Nursing, Faculty of Nursing, \\ Mansoura University ${ }^{\mathbb{I}}$, Lecturer of Medical -Surgical Nursing, Faculty of Nursing, Mansoura \\ University $^{2}$, Assistant professor of Critical Care and Emergency Nursing, Faculty of Nursing, \\ Mansoura University ${ }^{3}$
}

\begin{abstract}
Background: Deep vein thrombosis (DVT) is a major complication and preventable cause of morbidity and mortality among patients in the intensive care unit (ICU). The incidence of deep vein thrombosis in neurological ICU presumed to be higher reporting an incidence of 18 to $50 \%$. A nursing protocol that improves nurses' use of preventive measures for deep vein thrombosis is paramount. Aim: This study aimed to investigate the effect of nursing care protocol on deep vein thrombosis occurrence among critically neurological patients.Subjects and Method: Design: A quasi-experimental research design was used.Setting: study conducted at neurosurgery intensive care unit and neurological department in Mansoura University HospitalSubjects:a purposive sample of 60 patients (30 protocol patients group and 30 control group) participated in the study.. Routine care was applied to the control group while the protocol group received deep vein thrombosis care according to the protocol. Tools: data were collected using two tools; DVT Assessment Status Tool and DVT Incidence Monitoring Tool. Results: 26\% of studied patients in the control group developed DVT compared with $3 \%$ in the protocol group. A significant difference existed between the two groups after implementing the nursing protocol concerning exercise, elastic stock, and pneumatic compression $(\mathrm{P}<0.05)$. Conclusion and recommendations: The proposed protocol for nursing care is substantially successful in reducing DVT among critically neurological patients. It is recommended to train healthcare staff to use this protocol.
\end{abstract}

Keywords: Critically Neurological Patients, Deep Vein Thrombosis, Nursing Care Protocol. 


\section{INTRODUCTION}

Critically ill patients have an increased risk of DVT during their stay in the intensive care unit (ICU). The incidence of DVT in neuro ICU is presumed to be higher with studies reporting an incidence of 18 to $50 \%$ (Behera, Krishnakumar, \&RadhakrishnanMuthuchellappan, 2019).

Venous thromboembolism (VTE) is a frequent and potentially life-threatening complication that occurs despite the regular use of pharmacological prophylaxis in 4 to $15 \%$ of patients admitted to ICUs (Duranteau, Taccone, Verhamme, \&Ageno, 2018).

There are several risk factors in patients admitted to the neuro ICU that predisposes them to develop DVT. These factors include; increased risk of hypercoagulable states, immobility, head and spine injuries, brain malignancy, stroke, old age, osmotic diureticinduced dehydration, inherited thrombophilia (Nyquist et al., 2016). Failure to prevent DVT can result in post-thrombotic syndrome, recurrent thrombosis, readmission, delayed hospital discharge, and increase long-term morbidity (Kim, Bae, Kang\& Kim, 2019; Rinde et al., 2016).

Venous thrombosis occurs most commonly in the lower limbs. It can involve the superficial leg veins, the deep veins of the calf, and the proximal veins. Thrombosis of superficial veins is benign and self-limiting while thrombosis of the deep vein is a serious condition. At the same time, the thrombi in the superficial veins can extend into the deep veins and give rise to major pulmonary embolism (Schünemann et al., 2018)

Patients with DVT often have no symptoms, and therefore its detection is more likely to be delayed and prevention is mainly one of the most important nursing tasks. It recently suggested that the incidence of DVT used as a marker of quality in-hospital care, and use education programs of mechanical and pharmacological DVT prophylaxis improved by hospital-based (Ganau, Ligarotti, Meloni, \&Chibbaro, 2019).

The Autar DVT risk assessment scale is used for nursing assessment of all DVT patients. It has a simple scoring system to provide a patient risk category based on Virchow's triad of risk factors(Zhang, \& Liu, 2017). Comprehensive DVT risk factors assessment on admission and the use of the required type of prophylaxis for the patient at risk achieved the prevention of DVT (Wallis, \&Autar, 2001).

Mechanical measures include the use of a range of motion exercise, elastic stockings, adequate hydration unless contraindicated, and intermittent pneumatic compression 
devices. These measures should be started early for the patient at risk for DVT (Masotti et al., 2014).

The ROM exercises are one of the most important therapeutic interventions in the ICU to regain the patient's mobility and stability. Using ROM can improve venous return and could be primary DVT preventive measures and enhance the quality of life (Kisner, Colby \&Borstad, 2017)

Elastic stockings can give mechanical measures. It produces a gradient pressure that helps to restore the venous pump in the muscles of the calf by applying external pressure on the vein wall, allowing the valve cusps to meet each other. This movement allows the valves to transfer blood along the vein's path forward (Khan et al., 2017).

The intermittent pneumatic compression (IPC) device forces blood into deep veins from superficial veins and increases blood flow rate into the femoral veins. This eliminates venous stasis, pooling of blood, and venous congestion (Chibbaro et al., 2018).

Nurse-driven protocols allow eligible procedures to have autonomy for nursing practitioners in their particular place. Such protocols enhance protection and encourage quality in the delivery of treatment. Developing and using procedures guided by nurses promotes a safe work climate as well. Shared and active decision-making at all grades are critical for patient safety, quality of care (Barto, 2019)

The current nursing care protocol of DVT includes patients' assessment by Autar DVT risk assessment scale, implementation of preventive measures, and evaluation to promote optimal outcome for the neurological critically ill patients.

\section{Significance of the study}

According to the Centers for Disease Control and Prevention, it is estimated that between 300,000 and 600,000 people suffer from VTE each year, and up to 100,000 people die worldwide (Streiff et al, 2014). Nurses play an important role in recognizing critically ill patients who are at risk for DVT as they have direct interactions with patients during daily assessments. They must be aware of signs and symptoms of DVT to monitor for early detection and prevention of DVT (Nyquist, et al., 2016; Mohammed, Taha, \& Abdel-Aziz, 2018). 


\section{AIM OF THE STUDY:}

The present study aimed to investigate the effect of nursing care protocol on deep vein thrombosis occurrence among critically neurological patients.

\section{Research hypothesis:}

The protocol patients group that managed by applying nursing protocol has decreased in the incidence of DVT than the control group.

\section{SUBJECTS AND METHOD}

Design:A quasi-experimental research design was used

Setting:The study was carried out at the neurological ICU and neurological department in Mansura University Hospital;it provides care for patients with different neurological disorders.

Subjects: A purposive sample of 60 neurological patients selected randomly and divided into two equal groups. The control group was managed according to the hospital routine care for DVT prevention and the protocol group who have DVT nursing protocol. Newly admitted patients who were bedridden for more than 24 hours and at high risk for DVT as measured by the Autar scale were included in the study. While patients with DVT and who have abnormal prothrombin time were excluded from the study.

Tools of data collection:Two tools were used in this study

\section{Tool one: DVT AssessmentStatus}

This tool consisted of three parts

\section{Part (1): "Demographics \& Clinical Characteristics"}

This part covered the demographics and clinical characteristics of the participant patients including age, gender, date of admission, past medical history, present medical history, and level of consciousness.

\section{Part (2): "Autar DVT Risk Factor Assessment '}

This part was adopted from Wallis and Autar, 2001. It was used for both groups within the first 24 hours of admission to assess the patient at risk for DVT. It comprises seven risk categories including increasing age, build and body mass index (BMI), immobility, special DVT risk, trauma, surgery, and high-risk disease. Each factor was given a score and the total score was added up to find the patient risk category. The overall score offers a 
predictive DVT index,risk categories are classified as follows:No risk $<6$ scores, Low risk 6 - 10, Moderate risk 11-14, and High risk >15.

\section{Tool two: "DVT Incidence Monitoring"}

It compromises of two parts:

\section{Part (1): "DVT leg Manifestations Observational Checklist"}

This part was developed based upon relevant literature (Ramadan, Amr, \&Ashour, 2019) to assess patients' DVT leg manifestations such as calf pain, tenderness, skin warmth of the leg, skin color, swelling of limbs, calf erythema.It was used every two days from patient admission.

\section{Part (2): "DVT Confirming Diagnostic Studies"}

It was obtained from the patient medical record to monitor the occurrence of DVT among the participant patients as prothrombin time (to determine coagulation status) and Doppler finding (to assess blood supply in the veins of the lower limb and confirm DVT occurrence)

\section{Field work:}

\section{Preparation phase:}

Permission to conduct the study was obtained from the responsible authorities. Informed consent was obtained from the patients after explaining the purpose of the study. A pilot study was carried out on five patients to test the feasibility and applicability of the developed and the validity of the tools was revised by 5 critical and medical and surgical members for the jury.

\section{Implementation phase:}

\section{Data collected as follows:}

\section{A. Assessment}

- An initial assessment was carried out by the researcher for all neurological patients in both groups to collect the demographic characteristics, Clinical Characteristics were obtained from the patient's record using partl of tool one.

- Autar DVT risk factor assessment sheet (part 2 of tool I) was used for both groups within 24 hours of admission to assess the patient at risk. It comprises seven risk factors. A score was given for each factor and the total score was added to find the risk category of the patient being assessed. The total score provides a predictive index to DVT,risk categories 
are classified as follows: No risk $<6$ scores, Low risk $6-10$, Moderate risk 11-14, and High risk $>15$.

\section{B. Intervention}

- Nursing protocol from DVT was prepared for the protocol group. It was started from the admission until 2 weeks; and included the physical exercise as active and passive exercise, using elastic stocking, and external intermittent pneumatic compression (IPC) device.

- The passive exercises program consisted of 20 minutes of flexion-extension movements for both upper and lower limbs simultaneously.

- Elastic stockingsare tighter around the ankle and less tight around the calves and thighs. Compression stockings not only improve blood flow but also reduce swelling and pain. It started from the second day of admission until discharge.

- External IPC device was applied for the protocol group from the second day of admission until the patient was discharged. IPC devices consist of an inflatable arm, leg, or foot garment and an electrical pneumatic pump that fills compressed air into the garment. With cycle times and pressures that differ between devices, the garment is inflated and deflated intermittently. It was applied about two times in a day, started 20 minutes.

- The control group in this study was received routine hospital care regarding the prevention of deep vein thrombosis. The hospital routine includes low molecular weight heparin using for the eligible patients and change the patient's position every two hours.

\section{Evaluation phase:}

- After the implementation of the DVT nursing protocol, patients' condition for DVT was assessed by leg manifestations observational checklists (part I of tool II) such as calf pain, tenderness, skin warmth of the leg, skin color, swelling of limbs, calf erythema, and diagnostic study such as doppler and prothrombin time(part 2 of tool II) for both group among neurological patients,

- Then a comparison was done between the two groups to determine the effect of the protocol on the occurrence of DVT among neurological patients.

\section{Data analysis:}

The data collected was structured, tabulated, and statistically analyzed using version 19 of the Social Studies Statistical Package (SPSS). There was a measure of the number and percentage distribution of variables. Using the chi-square test, the relationship between variables was checked. In presence of small observations with expected values less than five, the chi-square test was considered inappropriate for statistical analysis, and Monte Carlo or Fisher exact test was used. The level of significant $\mathrm{P}<0.05$ 


\section{Validity}

Five experts from the Critical Care \& Emergency Nursing, and Med Surgery nursing Department assessed the content validity of the tool. Accordingly, essential modifications were applied.

\section{Reliability}

The overall reliability of the tool was tested using Cronbach's alpha test and found to be 0.87 .

\section{Pilot Study}

It was carried out on $10 \%$ of the total sample (6 patients) to test the clarity, feasibility, and applicability of the tools before data collection. Participants in the pilot study were excluded from the main study.

\section{Ethical Considerations}

Official permission to perform the study was obtained from the ethical approval of the Research Ethical Committee, Faculty of Nursing - Mansoura University, then permission from the authority of the hospital after clarifying the purpose of the study. Informed consent was obtained from patients' families after providing them with complete information about the study. Patients' families' participation in the study was voluntary and refusing to allow their patients to take part in the study would not affect his/her care or treatment. They were also informed that they had the right to seek to withdraw the patient from the study at any time without responsibility. Furthermore, they were assured about the confidentiality of patients' personal information.

\section{RESULTS:}

Table(1): shows a comparison between the studied groups according to the Autar DVT risk factor assessment sheet. It was found that no significant differences were found between the two groups, and they have the same risk for developing DVT.

Figure(1):defines a comparison between the studied groups regarding the Autar DVT risk assessment score.It was found that the Autar risk assessment score of the control group $54 \%$ was high risk and $43 \%$ were moderate risk with a mean of $14.60 \pm 1.87$, while it was found to be $50 \%$ high risk with a mean of $14.40 \pm 2.50$ in the protocol group with no significant difference between them. 
Figure (2): shows a comparison between the incidences of DVT among studied groups regarding Doppler findings. It was observed that $26 \%$ of patients in the control group had positive Doppler finding with evidence of DVT on the $2^{\text {nd }}$ week.

Table (2): shows a comparison between DVT manifestations of both legs between the studied groups after implementing the nursing protocol. Strong statistically significant differences could be obtained between them regarding pain, tenderness in the calf muscle, and warmth; as $P=0.001 * 0.002 * \& 0.000 *$ respectively. It can be seen that $16.7 \%$ of the control group had left calf pain, tenderness, and warmth on the second week of observation, $10 \%$ of the control group had complained of swelling on the right leg. $3.3 \%$ of patients in the control group had pyrexia. While $3.3 \%$ of the protocol group had left calf pain, tenderness warmth, and swelling on the second week of observation.

Table (3): shows a comparison between the studied group pre\&post-nursing protocol implementation regarding their prothrombin time (PT) and no significant differences were found.

Table (4): illustrates a comparison between the critically ill neurological patients (who developed and who did not develop DVT) after implementing the nursing protocol's measures to prevent DVT. A significant difference was found concerning exercise, elastic stocking,and pneumatic compression between the two groups $P=0.0001^{*}, 0.025^{*} \&$ $0.0001 *$ respectively. However, no difference was found regarding the use of anticoagulant therapies. 
Table (1): Comparison between the studied groups according to Autar DVT risk factor assessment sheet $(n=60)$ :

\begin{tabular}{|c|c|c|c|c|c|c|c|}
\hline \multirow{2}{*}{\multicolumn{2}{|c|}{ Risk factor for DVT }} & \multicolumn{2}{|c|}{$\begin{array}{l}\text { Control group } \\
(n=30)\end{array}$} & \multicolumn{2}{|c|}{$\begin{array}{l}\text { Protocol group } \\
(n=30)\end{array}$} & \multicolumn{2}{|c|}{ Significance test } \\
\hline & & $\mathbf{N}$ & $\%$ & $\mathbf{N}$ & $\%$ & $\overline{X^{2}}$ & $\mathbf{P}$ \\
\hline \multicolumn{8}{|c|}{ Age-specific group (years) } \\
\hline$<30$ & & 5 & 16.7 & 2 & 6.7 & \multirow{4}{*}{6.808} & \multirow{4}{*}{0.339} \\
\hline $30-45$ & & 7 & 23.3 & 10 & 33.3 & & \\
\hline $45-60$ & & 3 & 10 & 5 & 16.7 & & \\
\hline$>60$ & & 15 & 50 & 13 & 43.3 & & \\
\hline \multicolumn{8}{|l|}{ Gender } \\
\hline Males & & 12 & 40 & $\overline{10}$ & 33.3 & \multirow{2}{*}{5.83} & \multirow{2}{*}{0.345} \\
\hline Females & & 18 & 60 & 20 & 66.7 & & \\
\hline \multicolumn{8}{|c|}{ Body build/Body mass index (BMI) } \\
\hline -Average & $(20-25)$ & 5 & 16.7 & 4 & 13.3 & \multirow{4}{*}{11.161} & \multirow{4}{*}{0.084} \\
\hline -Overweight & 26-30) & 10 & 33.3 & 9 & 30 & & \\
\hline -Obese & $(31-40)$ & 15 & 50 & 16 & 53.4 & & \\
\hline -Very obese & $(>40)$ & 0 & 00 & 1 & 3.3 & & \\
\hline \multicolumn{8}{|l|}{ Mobility } \\
\hline -Very limite & & 10 & 33.3 & 9 & 30 & \multirow{3}{*}{5.500} & \multirow{3}{*}{0.240} \\
\hline -Chair boun & & 5 & 16.7 & 2 & 6.7 & & \\
\hline -Complete $\mathrm{b}$ & d rest & 15 & 50 & 19 & 63.3 & & \\
\hline \multicolumn{8}{|c|}{ Specific risk category: } \\
\hline \multicolumn{8}{|c|}{ - Oral contraceptives: } \\
\hline \multirow{2}{*}{\multicolumn{2}{|c|}{$-20-35$ years }} & 1 & 3.3 & 0 & 00 & \multirow{3}{*}{11.769} & \multirow{3}{*}{0.162} \\
\hline & & 0 & 00 & 0 & 00 & & \\
\hline \multicolumn{2}{|c|}{$\begin{array}{l}-35+\text { years } \\
- \text { Pregnancy/puernerium }\end{array}$} & 0 & 00 & 0 & 00 & & \\
\hline \multirow{17}{*}{$\begin{array}{l}\text { Risk } \\
\text { factors } \\
\text { related to } \\
\text { diagnosis } \\
(n=60)\end{array}$} & Trauma risk category & & & & & & \\
\hline & -Head injury & 3 & 10 & 9 & 30 & \multirow{4}{*}{18.246} & \multirow{4}{*}{0.108} \\
\hline & -Spinal injury & 5 & 16.7 & 4 & 13.3 & & \\
\hline & -Pelvic injury & 1 & 3.3 & 0 & 00 & & \\
\hline & -Lower limb injury & 1 & 3.3 & 2 & 6.7 & & \\
\hline & Surgical intervention & & & & & & \\
\hline & -Planned major & 5 & 16.7 & 2 & 6.7 & & \\
\hline & -Emergency major & 4 & 13.3 & 5 & 16.7 & & \\
\hline & -Thoracic & 0 & 0.0 & 3 & 10 & 18.246 & 0.108 \\
\hline & -Gynecological & 0 & 0.0 & 0 & 0.0 & & \\
\hline & -Abdominal & 0 & 0.0 & 0 & 0.0 & & \\
\hline & Current high-risk disease & & & & & & \\
\hline & -Ulcerative colitis & 2 & 6.7 & 1 & 3.3 & & \\
\hline & -Varicose veins & 1 & 3.3 & 2 & 6.7 & & \\
\hline & -Chronic heart disease & 4 & 13.3 & 1 & 3.3 & 12.476 & 0.568 \\
\hline & -Malignancy(active ulcer) & 2 & 6.7 & 1 & 3.3 & & \\
\hline & -Cerebrovascular accident & 2 & 6.7 & 0 & 0.0 & & \\
\hline
\end{tabular}




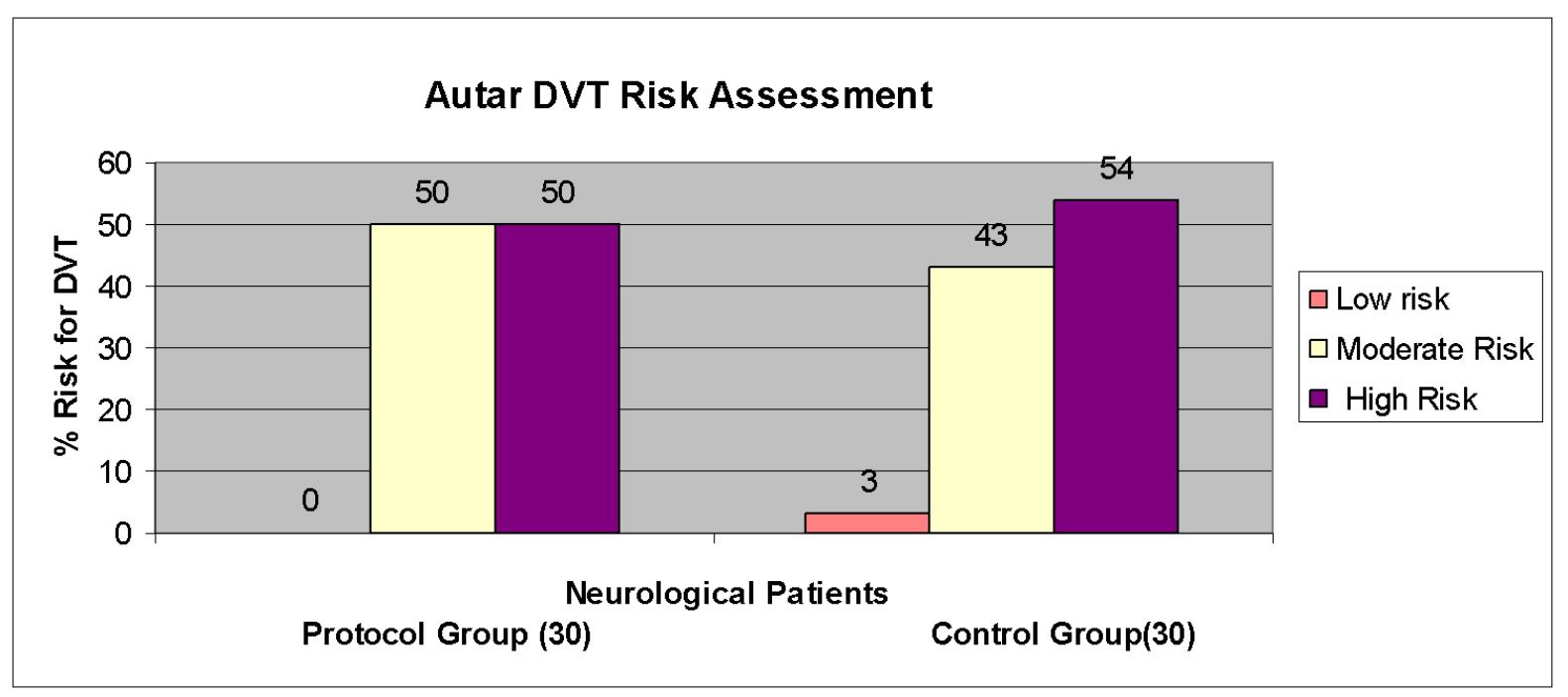

Figure (1): A comparison between the studied groups regarding the Autar DVT risk assessment score $(n=60)$

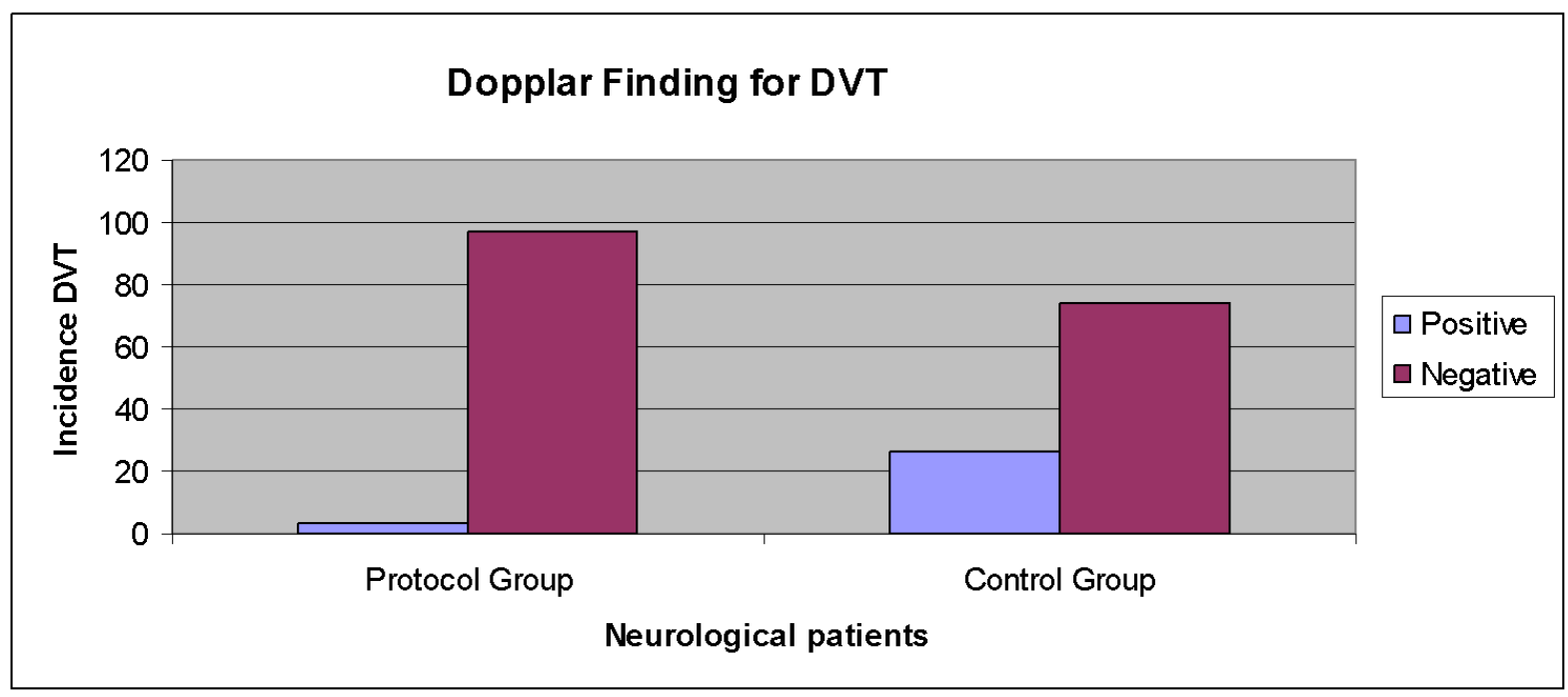

Figure (2): A comparison between the incidence of DVT among studied groups regarding Doppler findings $(n=60)$ 
Table (2): Comparison between DVT manifestations of both legs between the studied groups after implementing the safety protocol $(n=60)$ :

\begin{tabular}{|c|c|c|c|c|c|c|c|c|}
\hline \multirow{2}{*}{\multicolumn{3}{|c|}{ DVT Leg manifes tations }} & \multicolumn{6}{|c|}{ The studied neurological patients $(n=60)$} \\
\hline & & & \multicolumn{2}{|c|}{$\begin{array}{l}\text { Control } \\
\text { group }(n=30)\end{array}$} & \multicolumn{2}{|c|}{$\begin{array}{l}\text { Protocol } \\
\text { group }(\mathrm{n}=\mathbf{3 0})\end{array}$} & \multirow{4}{*}{$\begin{array}{l}\mathbf{X}^{2} \\
2.034\end{array}$} & \multirow[t]{2}{*}{$\mathbf{P}$} \\
\hline & & & $\mathrm{N}$ & $\%$ & $\bar{n}$ & $\%$ & & \\
\hline \multirow{4}{*}{ Pain } & \multirow[b]{2}{*}{1 week } & $\mathrm{R}$ & 1 & 3.3 & 0 & 0.0 & & \multirow{2}{*}{0.362} \\
\hline & & $\mathrm{L}$ & 1 & 3.3 & 0 & 0.0 & & \\
\hline & \multirow{2}{*}{2 week } & $\mathrm{R}$ & 3 & 10 & 1 & 3.3 & \multirow{2}{*}{14.93} & \multirow{2}{*}{$0.001 *$} \\
\hline & & $\mathrm{L}$ & 5 & 16.7 & 0 & 0.0 & & \\
\hline \multirow{4}{*}{$\begin{array}{l}\text { Tenderness in calf } \\
\text { muscle }\end{array}$} & \multirow{2}{*}{1 week } & $\mathrm{R}$ & 1 & 3.3 & 0 & 0.0 & \multirow{2}{*}{4.138} & \multirow{2}{*}{0.388} \\
\hline & & $\mathrm{L}$ & 1 & 3.3 & 0 & 0.0 & & \\
\hline & \multirow{2}{*}{2 week } & $\mathrm{R}$ & 2 & 6.7 & 1 & 3.3 & \multirow{2}{*}{13.24} & \multirow{2}{*}{$0.002 *$} \\
\hline & & $\bar{L}$ & 5 & 16.7 & $\overline{0}$ & 0.0 & & \\
\hline \multirow{4}{*}{ Warmth } & \multirow[t]{2}{*}{1 week } & $\mathrm{R}$ & 1 & 3.3 & 0 & 0.0 & \multirow{2}{*}{4.138} & \multirow{2}{*}{0.126} \\
\hline & & $\mathrm{L}$ & 2 & 6.7 & $\overline{0}$ & 0.0 & & \\
\hline & \multirow[t]{2}{*}{2 week } & $\mathrm{R}$ & 2 & 6.7 & $\overline{0}$ & 0.0 & \multirow{2}{*}{35.0} & \multirow{2}{*}{$0.000 *$} \\
\hline & & $\bar{L}$ & 5 & 16.7 & 1 & 3.3 & & \\
\hline \multirow{4}{*}{ Swelling of limb } & \multirow[t]{2}{*}{1 week } & $\overline{\mathrm{R}}$ & 1 & 3.3 & $\overline{0}$ & 0.0 & \multirow{2}{*}{4.138} & \multirow{2}{*}{0.388} \\
\hline & & $\mathrm{L}$ & 2 & 6.7 & 0 & 0.0 & & \\
\hline & \multirow[t]{2}{*}{2 week } & $\mathrm{R}$ & 3 & 10 & 1 & 3.3 & \multirow{2}{*}{4.138} & \multirow{2}{*}{0.126} \\
\hline & & $\mathrm{L}$ & 2 & 6.7 & 0 & 0.0 & & \\
\hline & 1 week & & 0 & 0.0 & $\overline{0}$ & 0.0 & & \\
\hline 1 уіехाа & 2 week & & 1 & 3.3 & $\overline{0}$ & 0.0 & 2.034 & 0.502 \\
\hline & 1 week & $\mathrm{R}$ & 1 & 3.3 & 0 & 0.0 & & \\
\hline Cant eryturima & 2 week & $\bar{L}$ & 2 & 6.7 & 0 & 0.0 & 0.510 & $0.17 /$ \\
\hline
\end{tabular}


Table (3): A comparison between the studied group pre\&postnursing protocol implementation regarding their prothrombin time $(\mathrm{PT})(\mathrm{n}=60)$ :

\begin{tabular}{|c|c|c|c|c|}
\hline \multirow{3}{*}{ Prothrombin time (PT) } & \multicolumn{2}{|c|}{ Neurological patients } & \multirow{3}{*}{ F-test } & \multirow{3}{*}{$\mathbf{P}$} \\
\hline & $\begin{array}{l}\text { Control group } \\
\qquad(\mathbf{n}=\mathbf{3 0})\end{array}$ & Protocol group $(n=30)$ & & \\
\hline & $\begin{array}{c}\text { Range } \\
\text { Mean (SD) }\end{array}$ & $\begin{array}{c}\text { Range } \\
\text { Mean (SD) }\end{array}$ & & \\
\hline Pre-safety protocol & $\begin{array}{l}12-15 \\
13.55(1.05)\end{array}$ & $\begin{array}{l}12-15 \\
13.55(1.05)\end{array}$ & 0.056 & 0.945 \\
\hline Post- safety protocol & $\begin{array}{l}11-17 \\
14.14 \pm 1.56\end{array}$ & $\begin{array}{l}13-17 \\
14.60 \pm 1.22\end{array}$ & 0.711 & 0.496 \\
\hline
\end{tabular}

Table (4): Comparison between the critically ill neurological patients (who developed and who didn't develop DVT) after implementing the protocol's safety measures to prevent DVT $(n=60)$ :

\begin{tabular}{|c|c|c|c|c|c|c|c|c|c|}
\hline \multirow{4}{*}{$\begin{array}{l}\text { protocol's safety measures } \\
\text { prevent DVT }\end{array}$} & \multicolumn{8}{|c|}{ Critically ill neurological patients } & \multirow{3}{*}{$\begin{array}{l}\text { Significance test } \\
\mathrm{X} 2 / \mathrm{P}\end{array}$} \\
\hline & \multicolumn{4}{|c|}{ Control group $(n=30)$} & \multicolumn{4}{|c|}{ Protocol $\operatorname{group}(\mathrm{n}=30)$} & \\
\hline & \multicolumn{2}{|c|}{$\begin{array}{c}\text { Didn't } \\
\text { develop DVT }\end{array}$} & \multicolumn{2}{|c|}{$\begin{array}{l}\text { Developed } \\
\text { DVT }\end{array}$} & \multicolumn{2}{|c|}{\begin{tabular}{|c|} 
Didn't \\
develop DVT
\end{tabular}} & \multicolumn{2}{|c|}{$\begin{array}{l}\text { Developed } \\
\text { DVT }\end{array}$} & \\
\hline & $\mathbf{N}$ & $\%$ & $\mathbf{n}$ & $\%$ & $\mathbf{N}$ & $\%$ & & $\%$ & \\
\hline Anticoagulant therapy: & & & & & & & & & \\
\hline -No anticoagulant & 8 & 26.7 & 0 & 0.0 & 21 & 70 & 0 & 0.0 & \\
\hline -Unfractionated heparin & 2 & 6.6 & 0 & 0.0 & 0 & 0.0 & 0 & 0.0 & 0.130 \\
\hline $\begin{array}{l}\text {-Low molecular weight } \\
\text { heparin }\end{array}$ & 12 & 40 & 8 & 26.7 & 8 & 26.7 & 1 & 3.3 & \\
\hline \multicolumn{10}{|l|}{ Exercise: } \\
\hline$-\mathrm{No}$ & 22 & 73.3 & 8 & 26.7 & 0 & 0.0 & 0 & 0.0 & \multirow{3}{*}{$0.0001 *$} \\
\hline -Active & 0 & 0.0 & 0 & 0.0 & 5 & 16.7 & 0 & 0.0 & \\
\hline -Passive & 0 & 0.0 & 0 & 0.0 & 24 & 80 & 1 & 3.3 & \\
\hline \multicolumn{10}{|l|}{ Elastic stocking: } \\
\hline - No & 9 & 30 & 6 & 20 & 0 & 0.0 & 0 & 0.0 & $0.025^{*}$ \\
\hline - Yes & 13 & 43.3 & 2 & 6.7 & 29 & 96.7 & 1 & 3.3 & \\
\hline \multicolumn{9}{|l|}{$\begin{array}{l}\text { Pneumatic } \\
\text { compression: }\end{array}$} & \multirow{3}{*}{$0.0001 *$} \\
\hline - No & 22 & 73.3 & 8 & 26.7 & 0 & 0.0 & 0 & 0.0 & \\
\hline - Yes & 0 & 0.0 & 0 & 0.0 & 29 & 96.7 & 1 & 3.3 & \\
\hline
\end{tabular}




\section{DISCUSSION}

Increasingly, DVT is recognized as a cause of mortality and morbidity among patients and contributes to a rising cost of healthcare services. Its management requires timely diagnosis and prompt commencement of treatment (Hepburn,Brown, Darvall, \&Hammerschlag, 2019). In Egypt, there is a high risk of developing VTE in more than one-third of all critically ill patients. Just a small percent of them, however, obtain adequate VTE prophylaxis. The prevention of VTE morbidity and mortality in these high-risk patients requires corrective steps (Elkattan, \&Elderiny, 2017; Soatova,\&Ergasheva, 2020)

The results of our study included significant gains in the implementation of safety measures, as a significant difference concerning exercise, elastic stock, and IPC between the two groups.

Patients in both groups were selected to have similar socio-demographic data. That was of great importance as variables such as their age, gender, body mass index, mobility, and diagnosis may influence the risk of DVT. More than half of the study participants were over 60 years of age. This can be explained by the occurrence of common internal diseases in elderly patients, such as congestive heart failure, chronic obstructive pulmonary disease (COPD), acute infections and atherosclerotic vascular disease, the risk of blood clots, and the risk of DVT. Besides, the same percent were females. That may be due to the hormonal changes that occur with contraception use, or pregnancy that increase the baseline risk of DVT during the reproductive years.

That was evidenced by an Egyptian study by Mohamed, Othman, El Alphy, and Sheble (2017) whose results showed a significant association between a patient's age and the risk of developing DVT, with increasing risk with older ages. That's also is in line with two Turkish studies by Susanto et al. 2014who illustrated that the patients' ages, female genders were significant factors that increased the risk of DVT.

Additionally, in Korea Lee et al. (2015) in their study detected that the advanced age, female gender were found to be risk factors for developing postoperative DVT. Also, Elkattan and Elderiny (2017) found that the relative risk for DVT was higher in females than in males. On contrary, Edeer, Comez, and Damar, (2018) in theirretrospective study found that the male gender compromised great risk for DVT. A previous study by Beckman, Hooper, Critchley and Ortel, (2010) revealed that males have a slightly higher overall incidence rate than females during the reproductive years; they have a slightly higher rate. 
In our study, another risk factor that was associated with developing DVT was obesity, as more than half of the studied patients in both groups were obese followed by one-third of those who were overweight, this may be attributed to obesity promotes impairment of the fibrinolysis and inflammation, both of which lead to an increased risk of forming thrombosis. Barbar and Prandoni(2017) reported that the prevalent risk factors for hospital-acquired DVT include older ages, acute medical illness, obesity, immobilization, undergoing surgeries, trauma, cancer and cancer therapies, central venous catheters, and histories of DVT.

Studies by Klovaite, Benn and Nordestgaard (2015) andChitkara and Saad, (2020) shown that obese people have almost twice the risk of DVT and that obese people under the age of 40 have almost five times the risk of DVT relative to those who are not. They concluded that the detection of risk factors for DVT would help to detect early risks.

The Autar DVT scale is a quantifiable and standardized assessment tool for evaluating patients with DVT risk and can increase the awareness of prevention among orthopedic surgery patients and health practitioners (Elkattan, \&Elderiny, 2017). As a baseline in the present study, the risk assessment was scored for the two groups; the two groups had both moderate and higher scores of developing DVT with no significant differences between them.

Regarding the presence of DVT manifestations in both legs among the studied group, strong statistically significant differences were found between the two groups concerning pain, tenderness in the calf muscle, and warmth as these manifestations were higher in the control group. Additionally, it was observed that less than one-third of patients in the control group had positive Doppler findings with evidence of DVT on the $2^{\text {nd }}$ week.

That is because the nursing protocol included performing the physical exercise (active and passive), elastic stocking, and IPC devices. The IPC cuffs enclosed completely the patients' extremity, filled with air, and compressed on it. This sequentially increased the blood flow, moved blood towards the patient's heart and so, oxygen-rich blood continues to flow in the arteries of the lower extremities and prevented blood clots.

This is consistent with Greenall and Davis (2020), which suggested that mechanical thromboprophylaxis is recommended for most surgical patients and other high-risk groups, such as patients with neurological disease, as the IPC system is believed to decrease DVT by increasing blood flow rate and decreasing hypercoagulability by inducing fibrinolytic activity of the vessel walls. Furthermore, Bircher and Chowdhury (2020), reported that the 
passive mechanism for reducing the risk of DVT is elastic stockings. The circumferential pressure that the stockings exert increases the velocity of blood flow and it facilitates venous return. The avoidance of passive venous distension is assumed to prevent subendothelial tears and hence the activation of clotting variables.

Arecent study conducted by $\mathrm{Li}$ et al. (2020)declared that in neurological patients there were still no general guidelines and uniform requirements for DVT prevention while nursing mechanical intervention and pharmacological anticoagulant therapy have been confirmed to minimize DVT effectively Shaikhouni, Baum and Lonser (2018). According to the latest American Society of Hematology 2021 guidelines, mechanical prophylaxis is preferred over pharmacological prophylaxis in routine neurosurgical patients (Cuker et al., 2021). Also in their retrospective study, Guo, Li, Zhong, Zhao and Zhang (2021) stated that compression stockings and IPC of the lower limbs are the most common mechanical methods for DVT prophylaxis.

The DVT patients in the study by McClain (2020) experienced pain, swelling, warmth, and tenderness in the calf muscle. Therefore, they concluded that in the dissemination of strategies across the health system, interprofessional cooperation, dedication, and feedback into the creation of a nurse-driven protocol were important. A pragmatic initiative to enhance patient care quality by growing understanding and standardization of VTE prophylaxis was the introduction of a nurse-driven protocol.

In the present study, when comparing the prothrombin time (PT) between the two groups before and after implementing the safety protocol, results revealed that there was no significant difference between them. This following Kim, Kim, Song, Hong, and Bae (2019) who assessed whether the IPC device would have been effective prophylaxis for the DVT and found laboratory findings such as D-dimer, $\mathrm{Hb}, \mathrm{PT}$, and a PTT were similar among the groups and it is safe to be used with no systematic complications.

There is little data on the efficacy of mechanical thromboprophylaxis, including IPC devices and elastic stocking. In particular, it is unclear whether additional protection is provided by adding IPC to pharmacological thromboprophylaxis (Arabi et al., 2018). Therefore, in this study, we could not neglect the use of anticoagulants however, no difference was found between the two groups regarding its usage.

The major gains in this study can directed toward the protocol items and that is the aim of this study. Conclusively, the benefits of this protocol include being non-invasive, 
requiring little monitoring, and the fact they pose no increased risk of bleeding and do not affect any of the body systems.

\section{CONCLUSION}

After application of nursing care protocol, the result of the present study is significantly efficacious in the reduction of deep vein thrombosis among critically neurological patients. The simultaneous use of intermittent pneumatic compression graduated compression stockings, and ROM exercise was effective than using the anticoagulant therapy alone for the prevention of DVT for patients who require prolonged bed rest.

\section{RECOMMENDATIONS}

- All critically ill patients should have a plan for active and passive range of motion exercise for the lower extremity unless contraindicated.

- Hospitals need protocols of care for risk assessment from DVT.

- Replication of the study on larger sample size.

\section{REFERENCES}

Arabi, Y., Al-Hameed, F., Burns, K. E., Mehta, S., Alsolamy, S., Almaani, M., ...\& Al-Dawood, A. (2018). Statistical analysis plan for the Pneumatic CompREssion for PreVENtingVenous Thromboembolism (PREVENT) trial: a study protocol for a randomized controlled trial. Trials, 19(1), 1-10.

Barbar S, Prandoni P. (2017).Scoring systems for estimating risk of venous thromboembolism in hospitalized medical patients.SeminThromb Hemost,43(5),460-468.

Barto, D. (2019).Nurse-driven protocols. Nursing2020 Critical Care, 14(4), 18-24.

Beckman, M. G., Hooper, W. C., Critchley, S. E., \&Ortel, T. L. (2010).Venous thromboembolism: a public health concern. American journal of preventive medicine, 38(4), S495-S501.

Behera, S. S., Krishnakumar, M., \&RadhakrishnanMuthuchellappan, M. P. (2019).Incidence of Deep Vein Thrombosis in Neurointensive Care Unit Patients-Does Prophylaxis Modality Make Any Difference?. Indian journal of critical care medicine: peer-reviewed, official publication of Indian Society of Critical Care Medicine, 23(1), 43.

Bircher, A., \&Chowdhury, A. (2020).Current DVT prophylaxis: a review. Orthopaedics and Trauma, 34(3), 161-167. 
Chibbaro, S., Cebula, H., Todeschi, J., Fricia, M., Vigouroux, D., Abid, H., ...\&Ganau, M. (2018). Evolution of prophylaxis protocols for venous thromboembolism in neurosurgery: results from a prospective comparative study on low-molecular-weight heparin, elastic stockings, and intermittent pneumatic compression devices. World neurosurgery, 109, e510-e516.

Chitkara, A., \&Saad, A. (2020).An Atypical Case of Morbid Obesity, Presenting With Deep Vein Thrombosis and Pulmonary Embolism. Cureus, 12(8).

Cuker, A., Tseng, E. K., Nieuwlaat, R., Angchaisuksiri, P., Blair, C., Dane, K., ...\&Schünemann, H. J. (2021).American Society of Hematology 2021 guidelines on the use of anticoagulation for thromboprophylaxis in patients with COVID-19. Blood advances, 5(3), 872-888.

Duranteau, J., Taccone, F. S., Verhamme, P., \&Ageno, W. (2018).European guidelines on perioperative venous thromboembolism prophylaxis: Intensive care. European Journal of Anaesthesiology| EJA, 35(2), 142-146.

Edeer, A. D., Comez, S., \&Damar, H. T. (2018).Prevalence and risk factors of venous thromboembolism in postoperative patients: A retrospective study. Pakistan Journal of medical sciences, 34(6), 1539

Elkattan, B. E. A., \&Elderiny, S. N. M. (2017).Effect of Nursing Care Guidelines on Preventing Deep Venous Thrombosis among Patients Undergoing Arthroplasty Surgery.International Journal of Novel Research in Healthcare and Nursing. 6, (2), pp: (757-774).

Ganau, M., Ligarotti, G. K., Meloni, M., \&Chibbaro, S. (2019).Efficacy and safety profiles of mechanical and pharmacological thromboprophylaxis. Annals of translational medicine, 7(6).

Greenall, R., \& Davis, R. E. (2020).Intermittent pneumatic compression for venous thromboembolism prevention: a systematic review on factors affecting adherence. $B M J$ open, 10(9), e037036.

Guo, P. C., Li, N., Zhong, H. M., Zhao, G. F., \& Zhang, M. (2021). Clinical Effectiveness of a Pneumatic Compression Device Combined with Low-Molecular-Weight Heparin for the Prevention of Deep Vein Thrombosis in Trauma Patients: a Retrospective Cohort Study. Pp: (1-19). 
Hepburn Brown, M., Darvall, J., \&Hammerschlag, G. (2019). Acute pulmonary embolism:

concise review of diagnosis and management. Internal medicine journal, 49(1), 1527.

Khan, M. T., Ikram, A., Saeed, O., Afridi, T., Sila, C. A., Smith, M. S., ...\&Shuaib, A. (2017). Deep vein thrombosis in acute stroke-a systemic review of the literature. Cureus, 9(12).

Kim, K. I., Kim, D. K., Song, S. J., Hong, S. J., \&Bae, D. K. (2019). Pneumatic compression device does not show effective thromboprophylaxis following total knee arthroplasty in a low incidence population. Orthopaedics\& Traumatology: Surgery \& Research, 105(1), 71-75.

Kim, W. J., Bae, S., Kang, C. J., \& Kim, D. Y. (2019). Clinical Factors Associated with Deep Vein Thrombosis in Rehabilitation Patients Suspected of Thromboembolism after Cerebral Infarction. Brain \& Neurorehabilitation, 13.

Kisner, C., Colby, L. A., \&Borstad, J. (2017). Therapeutic exercise: foundations and techniques. Fa Davis.

Klovaite, J., Benn, M., \&Nordestgaard, B. G. (2015).Obesity as a causal risk factor for deep venous thrombosis: a Mendelian randomization study. Journal of internal medicine, 277(5), 573-584.

Lee., Du Hyun Ro., Lee., Kwon., Sung., \& Park, (2015). Incidence of deep vein thrombosis after major lower limb orthopedic surgery: analysis of a nationwide claim registry. Yonsei medical journal, 56(1), 139.

Li, J., Ren, X., Zhu, X., Chen, H., Lin, Z., Huang, M., \&Gu, Z. (2020).Clinical Predictive Factors of Lower Extremity Deep Vein Thrombosis in Relative High-Risk Patients after Neurosurgery: A Retrospective Study. Disease Markers 2020 Jun 4; 2020.

Masotti, L., Di Napoli, M., Lorenzini, G., Godoy, D. A., Cappelli, R., Panigada, G \&Landini, G. (2014).Non-pharmacological Prophylaxis of Venous Thromboembolism in Acutely Ill Medical Patients. Cardiology and Angiology: an International Journal, 1-14.

McClain, R. (2020).Increasing Compliance with Sequential Compression Devices to Reduce Venous Thromboembolism. (Doctoral Dissertations , Walden University). 
Mohamed, A., Othman, W., El Alphy, B., \&Sheble, A. (2017).Effect of Implementing Nursing Care Guidelines on the Occurrence of Deep Vein Thrombosis among Orthopedic Patients. IOSR Journal of Nursing and Health Science, 6(3), 28.

Mohammed, A. S., Taha, N. M., \& Abdel-Aziz, E. M. (2018).Nurses' Performance Regarding Venous Thromboembolism Prophylaxis at Intensive Care Unit. Zagazig Nursing Journal, 14(1), 1-17.

Nyquist, P., Bautista, C., Jichici, D., Burns, J., Chhangani, S., DeFilippis, M., \& Meyer, K. (2016).Prophylaxis of venous thrombosis in neurocritical care patients: an evidence-based guideline: a statement for healthcare professionals from the Neurocritical Care Society. Neurocritical care, 24(1), 47-60.

Ramadan, R. M. E. S., Amr, T. E. S. E. S., \&Ashour, E. S. S. (2019).Calf muscle pump exercise and preventive measures: as means for prevention of deep vein thrombosis and its manifestations among a postpartum cesarean section. International journal of Nursing Didactics, 9(04), 49-60.

Rinde, L. B., Småbrekke, B., Mathiesen, E. B., Løchen, M. L., Njølstad, I., Hald, E. M., \& Hansen, J. B. (2016). Ischemic stroke and risk of venous thromboembolism in the general population: the Troms $\varnothing$ Study. Journal of the American Heart Association, 5(11), e004311.

Schünemann, H. J., Cushman, M., Burnett, A. E., Kahn, S. R., Beyer-Westendorf, J., Spencer, F. A., \&Wiercioch, W. (2018). American Society of Hematology 2018 guidelines for management of venous thromboembolism: prophylaxis for hospitalized and nonhospitalized medical patients. Blood advances, 2(22), 3198-3225.

Shaikhouni, A., Baum, J., \&Lonser, R. R. (2018).Deep vein thrombosis prophylaxis in the neurosurgical patient. Neurosurgery Clinics, 29(4), 567-574.

Streiff, M. B., Brady, P. J., Grant, A. M., Grosse, S. D., Wong, B., \&Popovic, T. (2014). CDC Grand Rounds: preventing hospital-associated venous thromboembolism. MMWR. Morbidity and mortality weekly report, 63(9), 190

Soatova, N.E., \&Ergasheva, Z.A. (2020). Diagnosis, treatment and prevention ofgynecological diseases. Re-health journal , (3-2), 56-67. 
Susanto, A. P., Krisnanda, C., Tan, D. S., Ong, H. Y., Pratama, D., \&Soeparwata, R. (2014).Incidence of venous thromboembolism among patients who underwent major surgery in a public hospital in Singapore. Medical Journal of Indonesia, 23(1), 36-41.

Wallis, M., \&Autar, R. (2001). Deep vein thrombosis: clinical nursing management. Nursing Standard (through 2013), 15(18), 47.

Zhang, C., \& Liu, Y. (2017).Application of Autar risk assessment scale for assessing the risk of deep vein thrombosis in joint patients with arthroplasty. Journal of Medical Postgraduates, 30(9), 968-972.

تأثير بروتوكول الرعاية التمريضية على حدوث جلطة الأوردة العميقة بين مرضى الأعصاب الحرجة

ا.م.د/ اسماء ابراهيم ابو سعدة ,د/ امل عيد عبد المنعم , ا.م.د/مروة فتح الله مصطفى

استاذ مساعد ـ تمربض العنابه الحرجة والطوارئ- كلية التصريض- جامعة المنصورة

مدرس تمريض باطنى جراحى -كلبة التمريض - جامعة الدنصورة

استاذ مساعد - تمربض العنايه الحرجة والطوارئ- كلبة التصريض - جامعة المنصورة

\section{الخلاصة}

تعتبر جلطة الأوردة العميقة هى أحد المضاعفات الرئيسية والسبب الذي يمكن الوقاية منه للمرض والوفيات بين المرضى في وحدة العناية المركزة، و نسبة الإصابة بجلطات الأوردة العميقة في وحدة العناية المركزة العصبية أعلى لهى حيث تبلغ نسبة الإصابة 18 إلى 50٪، و يعد بروتوكول التمريض الذي يحسن استخدام الممرضات للتدابير الوقائية من

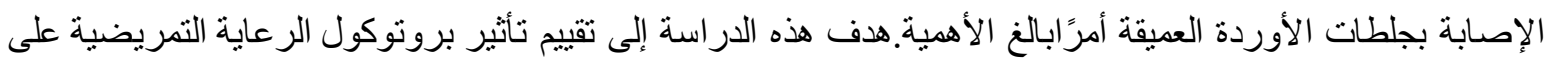
حدوث جلطة الأوردة العميقة بين مرضى الأعصاب الحرجة.تم استخدام تصميم بحث يشبه تجريبي مع عينةهادفة من 60 مريض (30 بروتوكول و 30 مريض تحكم ) تم اختبار هم من وحدة العناية المركزة لجر احة|لمخ و الأعصاب وقسم الأعصاب بمستشفى جامعة المنصورة ـ تم تطبيق الرعاية الروتينيةعلى مجموعة التحكم بينما ثلقت مجموعة

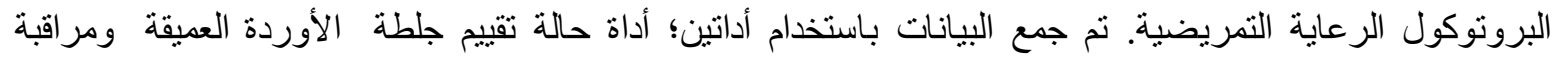
حدوثها. النتائج : يوجد فرق كبيربين المجموعتين بعد تتفيذ البروتوكول التمريضى فيما يتعلق بالتمارين الرياضية و الثر اب المرن والضغط الهو ائي (0.05 P P) الخلاصة والتوصية: إن البروتوكول المقترح للرعاية التمريضية ناجح بشكل كبيرفي تقليل الإصابة بجلطات الأوردة العميقة بين مرضى الاعصاب. يوصى بتدريب طاقم الرعاية الصحية على استخدام هذا البروتوكول.

الكلمات المرشدة : بروتوكول الرعاية التمريضية، جلطة الأوردة العميقة ،مرضى الاعصاب الحرجة 